\title{
Correction: Improved survival and graft function in ex vivo T-cell depleted haploidentical hematopoietic cell transplantation for primary immunodeficiency
}

Su Han Lum (D) Ali Sobh - Kay Carruthers - Zohreh Nademi • Helen Watson • Peter McNaughton • Sabeena Selvarajah · Angela Deyà-Martínez - Mario Abinun · Terry Flood • Andrew Cant · Sophie Hambleton • Andrew R. Gennery • Mary Slatter

Published online: 11 March 2021

(c) The Author(s), under exclusive licence to Springer Nature Limited 2020

Correction to: Bone Marrow Transplantation

https://doi.org/10.1038/s41409-020-01152-2

In the original version of the article the $\mathrm{Y}$ axis for Fig. 1e was incorrectly labelled "CD15+ donor chimerism, \%" instead of "T-lymphocyte donor chimerism, (\%)". This has now been corrected in both the PDF and HTML versions of the article. 

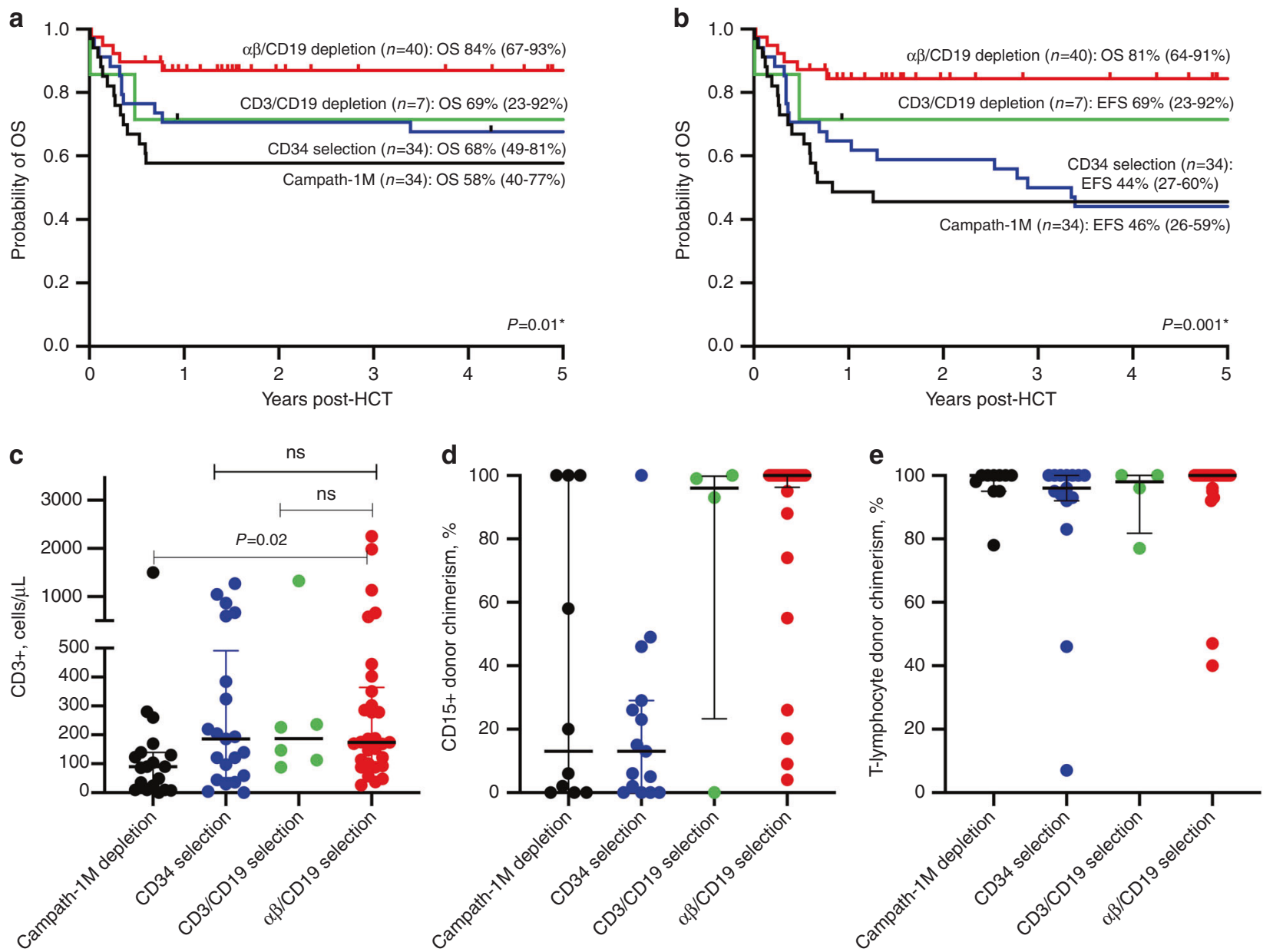

Fig. 1 Transplant outcomes according to ex vivo T-cell depletion methods. 